\title{
Future Imaging Alternatives: The Clinical Non-invasive Modalities in Diagnosis of Oral Squamous Cell Carcinoma (OSCC)
}

\author{
Esam Omar
}

Department of Oral \& Maxillofacial Surgery, College of Dentistry, Taibah University, Saudi Arabia

\begin{abstract}
Background: }}$ Oral squamous cell carcinoma (OSCC) has a remarkably high incidence worldwide, and a fairly serious prognosis. This is encouraging further research into advanced technologies for non-invasive methods of making early diagnoses, ideally in primary care settings. Method: In this article, the available objective Non-imaging methods for diagnosing OSCC have been reviewed. MEDLINE, EMBASE, the Cochrane Library, and CINAHL have been searched for advanced technologies of non-invasive methods in diagnosis of OSCC, including oral brush biopsy, optical biopsy, saliva-based oral cancer diagnosis and others. Results: Toluidine blue, one of the oldest non-invasive methods for diagnosing OSCC, is unreliable because of its subjectivity, as it is dependent on the experience of the examiner. The diagnosis of Oral carcinoma by Oral brush biopsy with exfoliative cytology based on nano-bio-chip sensor platform shows 97-100\% sensitivity and $86 \%$ specificity. Another promising non-invasive technique for OSCC diagnosis is saliva-based oral cancer diagnosis, which is an alternative to serum testing. Optical biopsy, which uses the technology of spectroscopy, can be used to detect changes at a sub-cellular level; thus, it provides information that may not be available with conventional histology with reliable sensitivity and specificity. Conclusion: It is clearly evident that screening and early effective detection of cancer and pre-cancerous lesions have the potential to reduce the morbidity and mortality of this disease. The imaging technologies are subjective procedures since all of them require interpretation and significantly affected by the examiner experience. These make further research for advanced objective procedures. Saliva-based oral cancer diagnosis and optical biopsy are promising objective non-invasive methods for diagnosing OSCC. They are easy to perform clinically at primary care set. They show promising pathways for future development of more effective method for the diagnosis of OSCC.
\end{abstract}

Keywords: Non-invasive methods, optical biopsy, Oral Cancer, saliva based diagnosis.

\section{INTRODUCTION}

Oral cancer is the eighth most common cancer worldwide and represents a significant disease burden. If detected at an early stage, survival from oral cancer is more than $90 \%$ at 5 years, whereas survival of patients presenting with late stage disease is only $30 \%$ [1]. There is a strong need to develop new non-invasive methods for diagnosing OSCC that can be used by primary care providers: these would improve the outcome of this disease. One of the oldest non-invasive techniques is the application of toluidine blue (TB), which has an affinity for nucleic acids, and therefore binds to nuclear material in tissues with a high DNA and RNA content [1]. However, because it is highly subjective, inexperienced practitioners cannot use this technique to diagnose OSCC. In 1986, Bouquot noted that as many as $10 \%$ of American adults have some form of oral abnormality that requires histopathological assessment. A reliable method for diagnosing oral mucosal abnormalities has been and remains the scalpel biopsy. Because most patients are fearful and stressed about the prospect of scalpel biopsies, oral brush biopsy has been developed as a less invasive substitute [2]. For decades, dental healthcare professionals have measured

*Address correspondence to this author at the Department of Oral \& Maxillofacial Surgery, College of Dentistry, Taibah University, Saudi Arabia; Tel: 00966569536708; Fax: 009661484947;

E-mail: esamomar@hotmail.com the buffering capacity and bacterial content of saliva to assess a person's risk of developing tooth decay. Today, scientific and technological advances in biochemistry, microbiology, and immunology are leading to the discovery of new biomarkers in saliva that can be used to detect systemic illnesses such as ischemic heart disease and heart failure and cancer [3, 4]. Saliva received a major boost in 2002 when the National Institute of Dental \& Craniofacial Research funded a project under title of (development and validation technologies for salivary based diagnostic). They have created a collaborated team of engineers, experts in nano-technology and biomediacal diagnostic fluids with scientists in oral biology to develop a point of care (lap-on ship) that is automated, miniaturized and multiplexed platform [3, 4]. Optical biopsy is based on the nature of light-tissue interactions, and involves different types of spectroscopy. These interactions include [5]:

- When energy from a radiating source is absorbed by a material, its absorption can be determined by measuring the fraction of energy transmitted through the material: absorption is inversely proportional to the energy transmitted.

- Emission indicates that radiative energy has been released by a material. A material's blackbody spectrum, a spontaneous emission spectrum, is determined by that material's temperature. Emission can be induced by vari- 
ous sources of energy, including flames, sparks, or electromagnetic radiation in the case of fluorescence.

- Elastic scattering and reflection spectroscopy determine how incident radiation is reflected or scattered by a material. Crystallography employs the scattering of highenergy radiation, such as X-rays and electrons, to examine the arrangement of atoms in proteins and solid crystals.

- Impedance spectroscopy studies the ability of a medium to impede or slow the transmission of energy. For optical applications, this is characterized by the index of refraction.

- Inelastic scattering phenomena involve an exchange of energy between the radiation and the matter that shifts the wavelength of the scattered radiation. These phenomena include Raman and Compton scattering.

- Coherent or resonance spectroscopy involves techniques in which radiating energy couples two quantum states of a material in a coherent interaction that is sustained by the radiating field. Because the coherence can be disrupted by other interactions, such as particle collisions and energy transfer, high intensity radiation is often required to sustain it. Nuclear magnetic resonance (NMR) spectroscopy is a widely used resonance method. Ultrafast laser methods are also now possible in the infrared and visible spectral regions. Many different technologies for optical biopsy have been developed according to the nature of light-tissue interactions. The most common non-invasive methods for diagnosing OSCC are summarized in Table $\mathbf{1}$.

Table 1. Summary of the most common non-invasive methods for diagnosing oral squamous cell carcinoma.

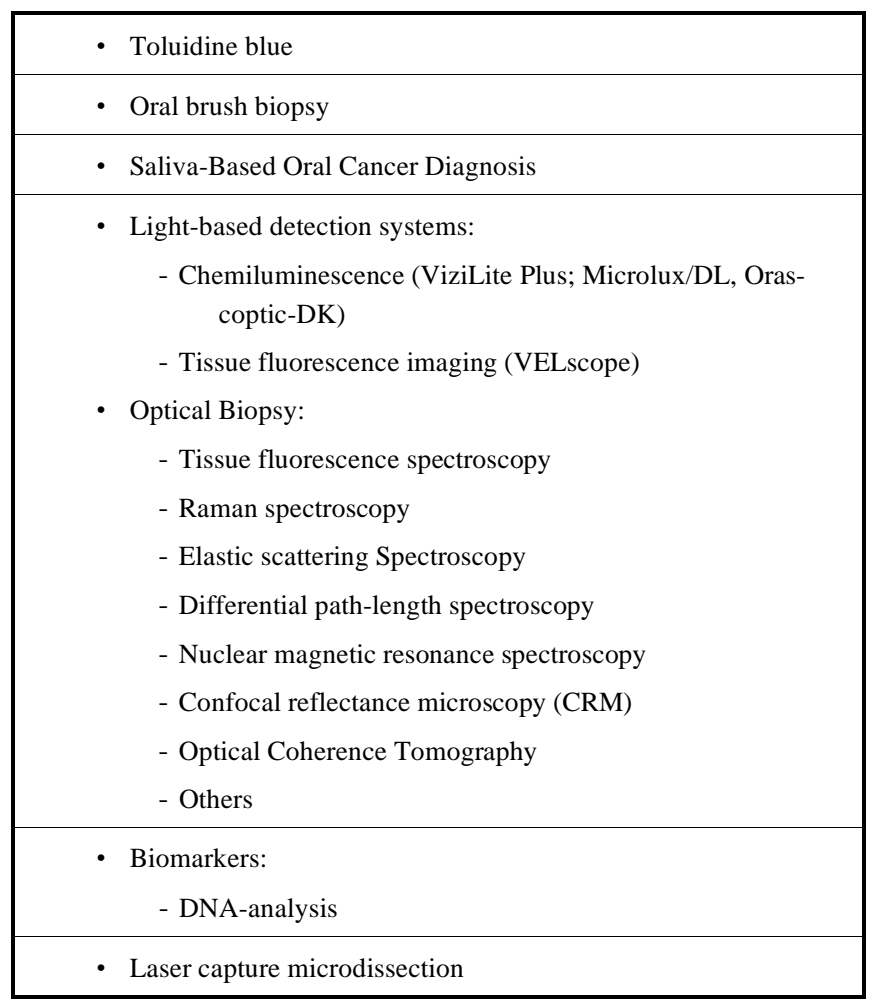

\section{TOLUIDINE BLUE STAINING}

Vital staining is the staining of living cells or tissues. The earliest technique was developed by Paul Ehrlich in 1885 and involved immersion of freshly removed tissue in methylated blue. There are two techniques for vital staining; namely, intravital staining within the living body (in vivo) and supravital staining outside the body, which usually involves preparation of slides of detached cells [6, 7]. Toluidine blue (TB) is a basic thiazine metachromatic dye with high affinity for acidic tissue components, thereby staining tissues rich in DNA and RNA. TB staining is a simple, inexpensive and sensitive tool for identifying early OSCC and high-grade dysplasias [8]. A $1 \%$ aqueous TB solution is applied for 30 seconds, this acidophilic metachromatic nuclear stain helps to differentiate areas of carcinoma in situ or invasive carcinoma from normal tissue. TB staining is highly sensitive and moderately specific for malignant lesions. It has less sensitivity for premalignant lesions, up to $58 \%$ false negatives having been reported for identifying mild-tomoderate dysplasia [8, 9]. Rosenberg and Cretin stated that the sensitivity of TB staining in oral cancer screening ranges from $93.5 \%$ to $97.8 \%$, and the specificity from $73.3 \%$ to $92.9 \%[6]$.

\section{ORAL BRUSH BIOPSY}

The goal of the highly sensitive and specific technique of oral brush biopsy is to provide a sample by a less painful and simpler means than scalpel or punch biopsy. The accuracy of brush tests has been the subject of many published studies. In every study in which oral lesions have been simultaneously assessed by both a brush biopsy and surgical biopsy, this test has been shown to have both sensitivity and specificity well over $90 \%[10,11]$. Oral brush biopsy uses a specially designed circular bristled brush that has been designed to access and sample all epithelial layers, including the basal cell layer and the most superficial aspects of the lamina propria [11]. Brush biopsy has many advantages: it is a chairside, easy to perform, painless test that can be used to evaluate any suspicious lesion, including common small white and red oral lesions, and to rule out dysplasia. Gupta et al. combined conventional oral brush biopsy with the application of TB to localize suspect mucosal areas [12]. Scully et al. stated that the sensitivity of brush biopsy in detection of dysplasia or OSCC is $71.4 \%$, whereas the specificity is only $32 \%$ [13]. Oral brush biopsy coupled with computer-assisted analysis has been developed as a technique for evaluating unexplained clinically detectable alterations of the surface epithelium of the oral mucosa; where cancer or pre-cancer is suspected, the sensitivity is up to $40 \%$ [11]. This technique is based on quantitative cytomorphometry and DNA aneuploidy with computer-assisted analysis [11]. However, the limited specificity of current cytology-based analysis is still a major impediment to early oral cancer detection and intervention $[10,14]$. Given that exfoliative cytology also gathers cellular DNA, RNA, and protein biomarkers, new diagnostic techniques targeting early tumour biomarkers and molecular transformation could enhance the role and utility of oral cytology in clinical diagnostics. Exfoliative cytology based on a nano-bio-chip sensor platform for oral cancer detection was described $[10,14,15]$. The diagnosis of Oral carcinoma by Oral brush biopsy with exfoliative cytology based on 
nano-bio-chip sensor platform shows $97-100 \%$ sensitivity and $86 \%$ specificity $[10,14,15]$.

\section{SALIVA-BASED ORAL CANCER DIAGNOSIS}

Saliva is considered a mirror of bodily health. The multifarious components of saliva not only protect the integrity of oral tissues, but also provide clues to various local and systemic conditions and diseases. These salivary components are constantly being explored as markers of various diseases and for monitoring general health [16]. In the past few years, multiplex biomarker detection systems have emerged through remarkable progress in the development of lab-on-achip and point-of-care technologies [17]. The goal of these efforts is to use nano/micro-electrical-mechanical development to build automated, miniaturized, and multiplexed platforms for rapid assays and readouts. In general, the principles of conventional enzyme-linked immunosorbent assay and/or nucleic acid hybridization are applied, often with either electrochemical sensors [18] or a microbead reactor [19, 20]. The electrochemical approach uses gold electrode arrays (multiplex chips) in which one set of electrodes (working, counter and reference electrodes) is applied, with a cyclic square wave electrical field to facilitate chemical reaction, for one analyte measurement, followed by amperometric readout [18].

Tumour cells may inhabit or produce biochemical substances referred to as tumour markers. These can be normal endogenous products that are produced at a greater rate in cancer cells or the products of newly switched on genes that remain quiescent in normal cells [21]. Tumour markers may be present as intracellular substances in tissues or as released substances in circulating body fluids such as serum, urine, cerebrospinal fluid, and saliva. Until recently, analyses for tumour markers were carried out in fluids other than saliva such as cerebrospinal fluid, blood and urine. However, with recent diagnostic technological advances, the role of saliva as a tool for diagnosis has advanced exponentially. Salivabased oral cancer diagnosis is a non-invasive alternative to serum testing with an overall accuracy rate of about $85 \%$. It is an effective modality for diagnosis, determining prognosis of oral cancer and monitoring post-therapy status [22-31].

\section{Genomic Substances}

Markers in the form of changes in the host DNA of dysplastic or cancer cells include point mutation, deletion, translocation, amplification, methylation, cyclin D1, epidermal growth factor receptor, microsatellite instability, and presence of human papillomavirus. Loss of heterozygosity (LOH) in chromosomes 3p, 9q, 13q, and 17p is considered an early event in oral carcinogenesis. In their study, Rosin et al. [32] found that allelic loss at $3 p$ and $9 q$ increases the risk of malignant transformation by 3.8 -fold and further increases the risk to 33 -fold when LOH occurs in chromosomes $4 \mathrm{q}, 8 \mathrm{p}, 11 \mathrm{q}, 13 \mathrm{q}$ and $17 \mathrm{p}$ in addition to the former. Mitochondrial DNA mutations have also been useful for detecting exfoliated OSCC cells in saliva [33]. Mutations have been identified by direct sequencing in $67 \%$ of saliva samples from OSCC patients [34]. p53 gene, which is located on chromosome $17 \mathrm{p} 13.1$, exhibits mutation in $50-70 \%$ of epithelial tumours $[35,36]$ and $\mathrm{LOH}$ of p53 allele has been reported in $22 \%$ of pre-cancer and $20 \%$ of oral cancer. Other genes related to p53 and the cell cycle, such as p16, $\mathrm{p} 27, \mathrm{p} 63$, and p73 have been found to be altered to varying degrees in oral cancer. [35, 36] Cyclin-dependent kinase inhibitor $2 \mathrm{~A}$, which is, involved in the retinoblastoma pathway of the cell cycle appears to be methylated in $23-67 \%$ of primary OSCC's. CDH1 a gene is responsible for cell adhesion, promotes metastasis when mutated, and shows promoter methylation in up to $85 \%$ of tumours [37]. Rosas et al. [38] identified aberrant methylation of at least one of these genes (p16, O6-methylguanine-DNA methyltransferase, death-associated protein kinase) in OSSC and detected promoter hypermethylation in $65 \%$ of matched saliva samples in OSCC patients. Amplification and over-expression of cMYCIN-MYC has been observed in $20-40 \%$ of oral cancers. Das et al. [39] have reported amplification of 11q13, which contains 1NT2, HST1, and cyclin D oncogenes, in 30-50\% of patients with oral cancer. However, the specificity and positive predictive value were higher for saliva than for serum $(88.0 \%$ vs. $59.8 \%$ and $54.2 \%$ vs. $28.8 \%$, respectively) [40].

\section{Transcriptomic Substances}

It has been speculated that salivary mRNA is contained in apoptotic bodies [41, 42] or actively released in exosomes or microvesicles. [43-45] Researchers [46] have compared the clinical accuracy of saliva versus blood RNA biomarker for oral cancer detection and found four RNA biomarkers that have a sensitivity and specificity of $91 \%$ and $71 \%$, respectively, and a collective receiver operator characteristic value of 0.95 . A study by Speight and Morgan found seven mRNA molecules to be significantly higher in OSCC patients than in healthy controls [47]: these included the following: (1) IL-8, [30, 48]; (2) IL-1 $\beta$, which takes part in signal transduction, proliferation, inflammation, and apoptosis [30, 48]; (3) dual specificity phosphatase 1 , which has a role in protein modification, signal transduction, and oxidative stress [30]; (4) H3 histone, family 3A, which has DNA binding activity [30]; (5) ornithine decarboxylase antizyme 1, which plays a part in polyamine biosynthesis $[30,48]$; (6) $\mathrm{S} 100$ calcium binding protein $\mathrm{P}$, which has a role in protein binding and calcium ion binding [30]; and (7) spermidine/spermine N1-acetyltransferase, which takes part in enzyme and transferase activity [30, 48].

\section{Proteomic Substances}

There is reportedly a substantial increase in salivary carbonyls $(246 \%)$ in OSCC patients, indicating that their epithelial cells are being exposed to significant free radical attack [49]. The sensitivity and specificity for carbonyls are $90 \%$ and $80 \%$, respectively. MMP-9 polymorphism has been shown to be strongly associated with increased risk of developing OSCC [50]. Shpitzer et al. [49-54] found a $39 \%$ increase in MMP-9 with a sensitivity of $100 \%$ and specificity of $79 \%$ in OSCC patients.

\section{LIGHT-BASED SYSTEMS}

Light-based systems depend on the assumption of absorption and reflection of light that differs between normal tissues and those with metabolic or structural changes. Vizil- 
ite Plus with TBlue system (Zila Pharmaceuticals, Phoenix, AR, USA), VELscope (LED Dental, White Rock, BC, Canada) Microlux/DL (AdDent, Danbury, CT, USA) and Orascoptic DK (Orascoptic, Middleton, WI, USA) are light-based oral cancer screening aids that have been developed with the aim of assisting identification of early stage precancerous and cancerous lesions. VELscope (LED Dental), a handheld device with an illuminated chemiluminescent stick, emits visible light in the $430 \mathrm{~nm}$ wavelength that causes fluorescent excitation of certain compounds in tissues. After the patients have rinsed their mouths with acetic acid, the oral cavity is examined. With Microlux (AdDent) and Vizilite (Zila Pharmaceuticals), the oral cavity is examined with a battery-powered fiberoptic visible light source rather than a chemiluminescent stick; again, prior rinsing with acetic acid is required. These devices are not sensitive or specific for diagnosing any type of oral lesion. Only examination of tissue can definitively determine the biologic behaviour of a lesion [55].

\section{OPTICAL BIOPSY}

\section{Fluorescence Spectroscopy}

Auto-fluorescence spectroscopy: Several mathematical methods have been proposed for evaluating recorded spectral features of fluorochromes and correlating these with disease states as a form of diagnostic optical biopsy [56, 57]. Compared with normal tissues, there are changes in the physical and chemical characteristics of malignant tissues caused by sub-cellular architectural changes, such as nuclear grade and nuclear to cytoplasm ratio, mitochondrial size and density, amount of keratin, and elastin to collagen ratio. It is well known that all tissues fluoresce and that malignant tissues fluoresce less than normal tissues: thus, they have different spectral characteristics. Studies have shown that normal oral mucosa emits more green fluorescence than neoplastic lesions when an ultraviolet or near ultraviolet light source is used [56, 57]. Auto-fluorescence imaging has recently been shown to improve detection of premalignant and malignant oral lesions [56, 57]. This method is based on absorption of ultraviolet and visible spectrum light by tissue fluorophore molecules (nicotinamide adenine dinucleotide [NAD] and hydrogen flavin adenine dinucleotide $[56,57][\mathrm{FADH}]$ in the epithelial layer and collagen and elastin in the stroma), which leads to emission of lower energy photons that can be detected as fluorescence from the oral mucosa. Optical fibres may be introduced into tissues through a hollow needle and the tissue signals interpreted by spectrometers $[56,57]$. The reported sensitivity of fluorescence spectroscopy technologies is up to $81 \%$ and the specificity $100 \%$ [58].

Enhanced dye fluorescence: Fluorescence can be slightly enhanced by exogenously applying fluorescent drugs such as 5-aminolevulinic acid, which induces protoporphyrin IX (protoporphyrin IX is an important precursor to biologically essential prosthetic groups such as heme, cytochrome c, and chlorophylls). Recent advances include the possibility of extracting true spectra of single fluorophores (chemical compounds that can re-emit light upon light excitation) by mathematically eliminating the undesired influences of scattering and absorption. In addition, it will soon be possible to precisely target tumour-specific enzymes with fluorescent markers ("smart probes"), which will improve both sensitivity and specificity [59-61]. Ebenezar et al. reported that a diagnostic algorithm based on discriminant function scores obtained by fluorescence excitation spectroscopy was able to distinguish well differentiated squamous cell carcinoma from normal lesions with a sensitivity of $100 \%$ and specificity of $100 \%$ [62].

Ratio imaging: This technique compares a photochemical or end metabolic product that is known to be increased in disease states with another product that is known to be depleted. For example, as described above, 5-aminolevulinic acid enhances protoporphyrin IX, which fluoresces red after excitation with blue light. The same excitation results in green fluorescence of molecules such as NAD and FADH, which are depleted in malignant tissues with a high metabolic rate [59-61]. Shin et al. have reported that the sensitivity of the fluorescence imaging techniques ranges from 60 to $97 \%$ and specificity from 75 to $99 \%$ [63].

\section{Raman Spectroscopy}

The Raman effect occurs when light impinges on a molecule and interacts with the electron cloud and bonds of that molecule. In the spontaneous Raman effect, which is a form of light scattering, a photon excites a molecule from the ground state to a virtual energy state. When the molecule relaxes, it emits a photon and goes into a different rotational or vibrational state. The difference in energy between the original state and this new state leads to a shift in the emitted photon's frequency away from the excitation wavelength [59-61, 64]. This laser-based spectroscopic technique is used to observe vibrational, rotational, and other low-frequency modes in a system, thus enabling chemical characterization and structure of molecules in a sample. Laser light interacts with molecular vibrations, phonons or other excitations in the system, resulting in the energy of the laser photons being shifted up or down. These shifts in energy give information about the vibrational modes in the system. This technique delivers a vibrational spectroscopic picture of tissue content, thus providing immediate real time histology ([59-61]. Raman is being investigated as a diagnostic tool for characterising cancer cells and early malignant changes and distinguishing these cells from normal cells. Raman spectroscopy has a distinct advantage over other optical techniques: it provides information on molecular composition and structure of living tissue [59-61, 64]. A significant problem associated with using Raman applications is that signals produced by the Raman effect are inherently weak. Raman bands generally overlap because of biological constituents, making it difficult to identify individual components correctly. The strong fluorescent background produced by biomedical samples may completely obscure the true Raman signals. The reported sensitivity of this technique is $80.5 \%$ and specificity $86.2 \%$ [64].

\section{Elastic Scattering Spectroscopy}

Elastic scattering spectroscopy (ESS) makes diagnoses by objective statistical and analytical methods, rather than by subjective interpretation of images. ESS provides optical geometrical information that is based on white light reflectance. In ESS, photons hit tissue and are backscattered with- 
out changes in wavelength. The relative intensity of this backscattering is influenced by the composition of the interrogated tissue, specifically the relative concentration of scatterers (e.g. nuclei, mitochondria, connective tissue) and absorbers (e.g. haemoglobin). A scattering event carries with it all the characteristics of the cellular components, which are called "scattering centres", pathological scattering centres may originate from disorganized epithelial orientation and architecture, changes in morphology of epithelial surface thickness and texture, cell crowding, increased distance from sub-epithelial collagen layer, enlargement and hyperchromicity of cell nucleus, increased concentration of metabolic organelles, and presence of abnormal protein packages or particles $[65,66]$. The ESS method senses micromorphology changes at the level of sub-cellular architectural changes, such as nuclear grade, nuclear to cytoplasm ratio, mitochondrial size and density, without actually imaging the microscopic structure. Because ESS detects changes at a subcellular level, it conveys information that may not be provided by conventional histology. Thus, ESS provides an optical signature of the tumour that greatly depends on the tumour's morphology $[67,68]$. The ESS system covers a range of 300-900 nm and uses a pulsed xenon arc lamp as the light source. The light emitted by cellular and sub-cellular organelles ranges from $330-850 \mathrm{~nm}$. The system has two fibreoptic probes, one for transmitting light into the tissue and the other for collecting scattered light. The tip of the probe is placed in direct contact with the lesion, a background measurement is taken, and then the lamp is activated. This is followed immediately (within $100 \mathrm{~ms}$ ) by taking an ESS measurement with the pulsed lamp. The background spectrum is then subtracted from the ESS spectrum. The entire measurement processing display takes less than 1 second [59-61]. In summary, ESS is a point measurement that uses appropriate optical geometry and is sensitive to the size and packing of dense subcellular components such as the nucleus, nucleolus, and mitochondria as well as absorption by haemoglobin [69-71]. Lovat et al. reported that the sensitivity for diagnosis of OSCC is $92 \%$ and specificity $60 \%$ and that ESS differentiates high risk sites from inflammation with a sensitivity and specificity of 79\% [72]. Muller et al. compared histopathologic findings with data obtained by ESS for normal and abnormal tissue in the oral cavity; they reported the accuracy of ESS was $91.6 \%$ for normal and $97 \%$ for abnormal tissue [73].

\section{Differential Path-length Spectroscopy}

Differential path-length spectroscopy (DPS), a recently developed fibre-optic point measurement technique, measures scattered photons that have travelled in predetermined path lengths. DPS is considered to be a form of ESS that has fixed photon path length, fixed photon visitation depth, and absolute measurement of absorbers. This technology was developed at the Erasmus Medical Centre, Rotterdam, the Netherlands [74]. The system uses a fibre-based diffuse reflection spectrometer with a tungsten-halogen lamp as a white light source. The first spectrometer uses a bifurcated fibre for illumination and collection. A second fibre carries diffusely reflected light to a second spectrometer. Each spectrometer records a spectrum with a slightly different wavelength scale. Subtraction of the two measurements selects superficially scattered light [74]. The spectrum is analysed mathematically and translated into a set of parameters that are related to the microvasculature and intracellular morphology. The signals give information about cell biochemistry, intracellular morphology and microvascular properties such as oxygen saturation and average vessel diameter. The reported sensitivity is $69 \%$ and specificity $85 \%$ [75].

\section{OPTICAL TOMOGRAPHY}

This technology uses light scattering either to construct an image, as in optical coherence tomography (OCT), or to measure the average size of different cell structures, thus providing objective information about degree of dysplasia, as in angle-resolved low coherence interferometry $(\mathrm{a} / \mathrm{LCI})$.

\section{Optical Coherence Tomography}

This is analogous to ultrasound imaging except that it uses light rather than sound. The high spatial resolution of OCT enables non-invasive in vivo "optical biopsy" and provides immediate and localized diagnostic information. The recent development of a Fourier domain mode lock swept source-based OCT system has helped to simultaneously achieve a high speed $(>100 \mathrm{kHz}$ A-scan rate) and good spatial resolution $(<4 \mu \mathrm{m})$. In addition, the development of various miniature scanning probes that provide high-speed threedimensional OCT pictures has been reported [59-61].

\section{Angle-resolved low Coherence Interferometry (A/LCI)}

A/LCI, an emerging biomedical imaging technology that uses the properties of scattered light to measure the average size of different cell structures, including cell nuclei, directly measures diagnostically relevant sub-cellular features of epithelial tissues up to $500 \mu \mathrm{m}$ below the surface. Unlike OCT, which is a subjective method because it requires image interpretation, a/LCI performs an objective analysis of tissue and delivers direct confirmation of precancerous disease to the physician. The technology shows promise as a clinical tool for in situ detection of dysplastic or precancerous tissue. The reported sensitivity is up to $100 \%$ and specificity $85 \%$ [76].

\section{NUCLEAR MAGNETIC RESONANCE SPECTROS- COPY}

Nuclear magnetic resonance spectroscopy (NMR) exploits the magnetic properties of certain atomic nuclei to determine the physical and chemical properties of atoms or the molecules in which they are contained. It relies on the phenomenon of nuclear magnetic resonance and can provide detailed information about the structure, dynamics, reaction state, and chemical environment of molecules. This technology allows three-dimensional study of atoms in molecules: the larger the magnet, the more sensitive the device. Using NMR, it is possible to view how protein links with DNA [59-61]. NMR has been used to identify metabolic signatures of oral squamous cell carcinoma compared with normal tissues [77-79]. Clinical studies have confirmed that the choline/creatine ratio is significantly higher in OSCC than in normal tissue [79, 80]. An NMR study of ex vivo tumour tissue has reported higher concentrations of taurine, choline, 
glutamic acid, lactic acid, and lipids in squamous cell tissue than in normal tissue [81]. In addition, overexpression of glucose transporters, especially of glucose transporter 1, which is associated with increased glycolytic metabolism, has been reported in OSCC [82]. Other authors who have examined the role of advanced glycated end products and increased numbers of their receptors in patients with primary gingival carcinoma have shown that expression of these receptors is correlates closely with the invasiveness of OSCC $[83,84]$.

\section{INFRARED SPECTROSCOPY}

This distinguishes different biomolecules by probing chemical bond vibrations and using these molecular and submolecular patterns to define and differentiate pathological from normal tissues $[85,86]$.

\section{BIOMARKERS (DNA ANALYSIS)}

DNA ploidy analysis after staining with Feulgen dye can determine the malignant potential of cells by comparing the findings with those of a reference group of cells. Computerassisted analysis to identify deviations in cellular DNA content has recently been designed [87].

\section{LASER CAPTURE MICRODISSECTION}

This allows precise study of cancer biology, thus helping to identify the molecular basis of malignancy [55]. This technology is based on extraction of cells from specimens in which the exact morphology of both the captured cells and the surrounding tissue are preserved. When rapid immunohistochemical staining techniques are combined with laser capture microdissection, more accurate microdissection of cellular subsets can be obtained [88]. It may also help to detect biomarkers and protein fingerprint models for early detection of OSCC.

\section{LAB-ON-A-CHIP}

This term refers to the adaptation, miniaturization, integration, and automation of analytical laboratory procedures into a single device or electronic chip. Lab-on-a-chip utilizes membrane-associated cell proteins to detect dysplastic changes that are singularly expressed on the cell membranes of dysplastic and cancer cells, as well as their unique gene transcription profiles [89].

\section{CONCLUSION}

The imaging technologies are subjective procedures since all of them require interpretation and significantly affected by the examiner experience. TB is one of the oldest noninvasive methods for diagnosing OSCC. Being highly sensitive and moderately specific for malignant lesions, it can be used for screening and ruling out of suspicious areas. However, it is an unreliable technique because it is highly subjective and depends on the experience of the investigator. Unlike sampling of uterine cervix cells, analysis of surface epithelial cells of the oral cavity and oropharynx by standard exfoliative cytology (brush biopsy) has proven to be unreliable, identifying as few as $31 \%$ of dysplastic tissues [12]. Computerized analysis of oral brush biopsy specimens within the context of premalignant lesions reportedly has a positive predictive value of $58.3 \%$ and, with the support of molecular markers including tenascin and cytokeratins, accurate diagnoses are achievable [11]. Saliva-based oral cancer diagnosis and optical biopsy are promising non-invasive methods for diagnosing OSCC with high sensitivity and reliable specificity that are easy for primary care practitioners to perform clinically. These technologies provide objective information and do not require special experience for interpretation of the information obtained. They could be widely used in the near future as reliable routine modalities for oral cancer diagnosis and evaluation of the degree of dysplasia of pre-cancerous lesions. It is clearly evident that screening and early detection of cancer and its precursors have the potential to reduce the morbidity and mortality of this disease. These technologies may change the consequences of this disease in the near future.

\section{CONFLICT OF INTEREST}

The authors confirm that this article content has no conflict of interest.

\section{ACKNOWLEDGEMENTS}

Declared none.

\section{REFERENCES}

[1] Epstein JB, Oakley C, Millner A, Emerton S, van der Meij E, Le N. The utility of toluidine blue application as a diagnostic aid in patients previously treated for upper oropharyngeal carcinoma. Oral Surg Oral Med Oral Pathol Oral Radiol Endod 1997; 83: 537-47.

[2] Bouquot JE. Common oral lesions found during a mass screening examination. J Am Dent Assoc 1986; 112(1): 50-7.

[3] Mandel ID. Salivary diagnosis: more than a lick and a promise. J Am Dent Assoc 1993; 124: 85-7.

[4] Lee JM, Garon E, Wong DT. Salivary diagnostics. Orthod Craniofac Res 2009; 12(3): 206-11. doi: 10.1111/j.16016343.2009.01454.x. Review.

[5] Crouch Stanley, Skoog Douglas A. Principles of instrumental analysis. Australia: Thomson Brooks/Cole. ISBN 2007; 0-49501201-7.

[6] Culling CF, Allison TR. Cellular Pathology Technique. $4^{\text {th }}$ ed. London: Butterworths 1985.

[7] Rosenberg D, Cretin S. Use of meta-analysis to evaluate tolonium chloride in oral cancer screening. Oral Surg Oral Med Oral Pathol 1989; 67: 621-7.

[8] Mashberg A. Toluidine blue. J Can Dent Assoc 1995; 61(11): 922 44.

[9] Martin IC, Kerawala CJ, Reed M. The application of toluidine blue as a diagnostic adjunct in the detection of epithelial dysplasia. Oral Surg Oral Med Oral Pathol Oral Radiol Endod 1998; 85(4): 444-6.

[10] Scheifele C, Schmidt-Westhausen AM, Dietrich T, Reichart PA. The sensitivity and specificity of the OralCDx technique: evaluation of 103 cases. Oral Oncol 2004; 40(8): 824-8.

[11] Sciubba JJ. Improving detection of precancerous and cancerous oral lesions. Computer-assisted analysis of the oral brush biopsy. $\mathbf{J}$ Am Dent Assoc 1999; 130: 1445-57.

[12] Gupta A, Singh M, Ibrahim R, Mehrotra R. Utility of toluidine blue staining and brush biopsy in precancerous and cancerous oral lesions. Acta Cytol 2007; 51(5): 788-94.

[13] Scully C, Bagan JV, Hopper C, Epstein JB. Oral cancer: current and future diagnostic techniques. Am J Dent 2008; 21(4): 199-209.

[14] Poate TW, Buchanan JA, Hodgson TA, et al. An audit of the efficacy of the oral brush biopsy technique in a specialist Oral Medicine unit. Oral Oncol 2004; 40(8): 829-34.

[15] Weigum SE, Floriano PN, Redding SW, et al. Nano-bio-chip sensor platform for examination of oral exfoliative cytology.Cancer Detect Prevent 2010; 3(4): 518-28. 
[16] Mandel ID. The diagnostic uses of saliva. J Oral Pathol Med 1990; 19(3): 119-25.

[17] Jokerst JV, McDevitt JT. Programmable nano-bio-chips: multifunctional clinical tools for use at the point-of-care. Nanomed 2010; 5(1): 143-55.

[18] Wei F, Patel P, Liao W, et al. Electrochemical sensor for multiplex biomarkers detection. Clin Cancer Res 2009; 15(13): 4446-52.

[19] Floriano PN, Christodoulides N, Miller CS, et al. Use of salivabased nano-biochip tests for acute myocardial infarction at the point of care: a feasibility study. Clin Chem 2009; 55(8): 1530-8.

[20] Liu C, Qiu X, Ongagna S, et al. A timer-actuated immunoassay cassette for detecting molecular markers in oral fluids. Lab Chip 2009; 9(6): 768-76.

[21] Malati T. Tumour markers: an overview. Indian J Clin Biochem 2007; 22(2): 17-31.

[22] Zimmermann BG, Park NJ, Wong DT. Genomic targets in saliva. Ann N Y Acad Sci 2007; 1098: 184-91.

[23] Xie H, Onsongo G, Popko J, et al. Proteomics analysis of cells in whole saliva from oral cancer patients via value-added threedimensional peptide fractionation and tandem mass spectrometry. Mol Cell Proteomics 2008; 7(3): 486-98.

[24] Williams MD. Integration of biomarkers including molecular targeted therapies in head and neck cancer. Head Neck Pathol 2010; 4(1): 62-9.

[25] Sugimoto M, Wong DT, Hirayama A, et al. Capillary electrophoresis mass spectrometry-based saliva metabolomics identified oral, breast and pancreatic cancer-specific profiles. Metabolomics 2010; 6(1): 78-95

[26] Lee JM, Garon E, Wong DT. Salivary diagnostics. Orthod Craniofac Res 2009; 12(3): 206-11.

[27] $\mathrm{Hu} \mathrm{S}$, Arellano M, Boontheung P, et al. Salivary proteomics for oral cancer biomarker discovery. Clin Cancer Res 2008; 14(19): 6246-52.

[28] Bigler LR, Streckfus CF, Dubinsky WP. Salivary biomarkers for the detection of malignant tumors that are remote from the oral cavity. Clin Lab Med 2009; 29(1): 71-85.

[29] Bilodeau E, Alawi F, Costello BJ, et al. Molecular diagnostics for head and neck pathology. Oral Maxillofac Surg Clin North Am 2010; 22(1): 183-94.

[30] Zimmermann BG, Wong DT. Salivary mRNA targets for cancer diagnostics. Oral Oncol 2008; 44: 425-9.

[31] Handschel J, Oz D, Pomjanski N, Depprich R, et al. Additional use of DNA-image cytometry improves the assessment of resection margins. J Oral Pathol Med 2007; 36(8): 472-5.

[32] Rosin MP, Cheng X, Poh C, et al. Use of allelic loss to predict malignant risk for low-grade oral epithelial dysplasia. Clin Cancer Res 2000; 6: 357-62.

[33] Markopoulos AK, Michailidou EZ, Tzimagiorgis G. Salivary markers for oral cancer detection. Open Dent J 2010; 4: 171-8.

[34] Fliss MS, Usadel H, Caballero OL, et al. Facile detection of mitochondrial DNA mutations in tumors and bodily fluids. Science 2000; 287: 2017-9.

[35] Wanninayake M Tilakaratne. The cancer handbook. Oral cavity and major and minor salivary glands; $2^{\text {nd }}$ ed. United States: John Wiley and Sons Ltd 2007; pp. 1-15.

[36] Boyle JO, Hakim J, Koch W, et al. The incidence of p53 mutations increases with progression of head and neck cancer. Cancer Res 1993; 53: 4477-80.

[37] Ha PK, Califano JA. Promoter methylation and inactivation of tumour-suppressor genes in oral squamous-cell carcinoma. Lancet Oncol 2006; 7: 77-82.

[38] Rosas SL, Koch W, Da Costa Carvalho MG, et al. Promoter hypermethylation patterns of p16, O6-methylguanine-DNAmethyltransferase, and death-associated protein kinase in tumors and saliva of head and neck cancer patients. Cancer Res 2001; 61: 939-42.

[39] Das BR, Nagpal JK. Understanding the biology of oral cancer. Med Sci Monit 2002; 8: RA 258-67.

[40] Chien DX, Schwartz PE. Saliva and serum CA 125 assays for detecting malignant ovarian tumors. Obstet Gynecol 1990; 75: 701 4.

[41] Hasselmann D, Rappl G, Tilgen W, Reinhold U. Extracellular tyrosinase mRNA within apoptotic bodies is protected from degradation in human serum. Clin Chem 2001; 47: 1488-9.

[42] Ratajczak J, Wysoczynski M, Hayek F, Janowska-Wieczorek A, Ratajczak MZ. Membrane-derived microvesicles: Important and underappreciated mediators of cell-to-cell communication. Leukemia 2006; 20: 1487-95.

[43] García JM, García V, Peña C, et al. Extracellular plasma RNA from colon cancer patients is confined in a vesicle-like structure and is mRNA-enriched. RNA 2008; 14: 1424-32.

[44] Simpson RJ, Jensen SS, Lim JW. Proteomic profiling of exosomes: Current perspectives. Proteomics 2008; 8: 4083-99.

[45] Skog J, Würdinger T, van Rijn S, et al. Glioblastoma microvesicles transport RNA and proteins that promote tumour growth and provide diagnostic biomarkers. Nat Cell Biol 2008; 10:1470-6.

[46] Wong DT. Salivary diagnostics powered by nanotechnologies, proteomics and Genomics. JADA 2006; 137: 313-21.

[47] Speight PM, Morgan PR. The natural history and pathology of oral cancer and precancer. Comm Dent Health 1993; 10(Suppl 1): 3141.

[48] Wong DT. Salivary diagnostics powered by nanotechnologies, proteomics and Genomics. JADA 2006; 137: 313-21.

[49] Shpitzer T, Hamzany Y, Bahar G, et al. Salivary analysis of oral cancer biomarkers. Br J Cancer 2009; 101: 1194-8.

[50] Vairaktaris E, Vassiliou S, Nkenke E, et al. A metalloproteinase-9 polymorphism which affects its expression is associated with increased risk for oral squamous cell carcinoma. Eur J Surg Oncol 2008; 34: 450-5.

[51] St John MA, Li Y, Zhou X, Denny P, Ho CM, Montemagno C. Interleukin 6 and interleukin 8 as potential biomarkers for oral cavity and oropharyngeal squamous cell carcinoma. Arch Otolaryngol Head Neck Surg 2004; 130: 929-35.

[52] Rajkumar K, Kumar AR, Ramyamalini V, et al. Estimation of serological and salivary biomarkers in patients with Oral Squamous cell carcinoma, premalignant lesions and conditions. SRM Univ J Dent Sci 2010; 1: 14-9.

[53] Rhodus NL, Ho V, Miller CS, Myers S, Ondrey F. NF-kappa B dependent cytokine levels in saliva of patients with oral preneoplastic lesions and oral squamous cell carcinoma. Cancer Detect Prev 2005; 29: 42-5.

[54] Arellano-Garcia ME, Hu S, Wang J, et al. Multiplexed immunobead-based assay for detection of oral cancer protein biomarkers in saliva. Oral Dis 2008; 14: 705-12.

[55] Mehrotra R, Hullmann M, Smeets R, Reichert TE, Driemel O. Oral cytology revisited. J Oral Pathol Med 2009; 38: 161-6.

[56] Betz CS, Makriniotis T, Stepp H, Jerjes W, Upile T, Hopper C, Leunig A. Diagnosis of head \& neck malignancy using fluorescence spectroscopy and imaging. Head Neck Oncol 2009; 1(Suppl 1): O4.

[57] Stepp H, Johansson A, Betz CS, Leunig A. Fluorescence spectroscopy and fluorescence imaging for tissue diagnostics: principles and methods. Head \& Neck Oncology 2009; 1(Suppl 1): O3.

[58] Kulbersh BD, Duncan RD, Magnuson JS, Skipper JB, Zinn K, Rosenthal EL. Sensitivity and specificity of fluorescent immunoguided neoplasm detection in head and neck cancer xenografts. Arch Otolaryngol Head Neck Surg 2007; 133(5): 511-5.

[59] Suhr MA, Hopper C, Jones L, George JG, Bown SG, MacRobert AJ. Optical biopsy systems for the diagnosis and monitoring of superficial cancer and precancer. Int J Oral Maxillofac Surg 2000; 29(6): 453-7.

[60] Upile T, Jerjes W, Sterenborg HJ, et al. Head \& neck optical diagnostics: vision of the future of surgery. Head Neck Oncol 2009; 1: 25. doi: 10.1186/1758-3284-1-25.

[61] Jerjes W, Upile T, Petrie A, et al. Clinicopathological parameters, recurrence, locoregional and distant metastasis in 115 T1-T2 oral squamous cell carcinoma patients. Head Neck Oncol 2010; 2: p.9.

[62] Ebenezar J, Ganesan S, Aruna P, Muralinaidu R, Renganathan K, Saraswathy TR. Noninvasive fluorescence excitation spectroscopy for the diagnosis of oral neoplasia in vivo. J Biomed Opt 2012; 17(9).

[63] Dongsuk Shin, Nadarajah Vigneswaran, Ann Gillenwater, Rebecca Richards, Kortum A. Advances in fluorescence imaging techniques to detect oral cancer and its precursors. Future Oncol 2010; 6(7): 1143-54.

[64] Duraipandian S, Sylvest Bergholt M, Zheng W, et al. Real-time Raman spectroscopy for in vivo, online gastric cancer diagnosis during clinical endoscopic examination. J Biomed Opt 2012; 17(8): 081418 .

[65] Jerjes W, Swinson B, Pickard D, Thomas GJ, Hopper C. Detection of cervical intranodal metastasis in oral cancer using elastic scattering spectroscopy. Oral Oncol 2004; 40(7): 673-8. 
[66] Sharwani A, Jerjes W, Salih V, et al. Assessment of oral premalignancy using elastic scattering spectroscopy. Oral Oncol 2006; 42(4): 343-9.

[67] Hopper C. The clinical application of elastic scattering spectroscopy in the head and neck. Head Neck Oncol 2009; 1(Suppl 1): O2.

[68] Bigio IJ. Elastic light scattering spectroscopy for the detection of pre-cancer: an overview. Head Neck Oncol 2009; 1(Suppl 1): O1.

[69] Lovat LB, Bown SG. Elastic scattering spectroscopy for detection of dysplasia in Barrett's esophagus. In: van Dam J, Ed.Gastrointestinal endoscopy clinics of North America: optical biopsy, Vol 14. Amsterdam: Elsevier 2004; 517: 507-17.

[70] Mourant JR, Canpolat M, Brocker C, et al. Light scattering from cells: the contribution of the nucleus and the effects of proliferative status. J Biomed Opt 2000; 137: 5131-7.

[71] Mourant JR, Hielscher AH, Eick AA, et al. Evidence of intrinsic differences in the light scattering properties of tumorigenic and nontumorigenic cells. Cancer 1998; 374: 84366-74.

[72] Lovat LB, Johnson K, Mackenzie GD, Clark BR, et al. Elastic scattering spectroscopy accurately detects high grade dysplasia and cancer in Barrett's oesophagus. Gut 2006; 55(8): 1078-83. Epub 2006 Feb 9.

[73] Müller MG, Valdez TA, Georgakoudi I, et al. Spectroscopic detection and evaluation of morphologic and biochemical changes in early human oral carcinoma. Cancer 2003; 97(7): 1681-92.

[74] Amelink A, Sterenborg HJ, Bard MP, Burgers SA: In vivo measurement of the local optical properties of tissue by use of differential path-length spectroscopy. Opt Lett 2004; 29(10): 1087-9.

[75] Sterenborg HJCM, Witjes MJH, De Visscher S, Amelink A. Differential pathlength spectroscopy for diagnosis of head and neck cancer. Head Neck Oncol 2009; 1(Suppl 1): O7.

[76] Wax A, Terry NG, Dellon ES, Shaheen NJ, Gastroenterol 2011; 141: 443-7.

[77] Adalsteinsson E, Spielman DM, Pauly JM, Terris DJ, Sommer G, Macovski A. Feasibility study of lactate imaging of head and neck tumors. NMR Biomed 1998; 11: 360-9.

[78] El-Sayed S, Bezabeh T, Odlum O, et al. An ex vivo study exploring the diagnostic potential of $\mathrm{H}-1$ magnetic resonance spectroscopy in squamous cell carcinoma of the head and neck region. Head Neck J Sci Spec 2002; 24: 766-72.
[79] Maheshwari SR, Mukherji SK, Neelon B, et al. The choline/creatine ratio in five benign neoplasms: comparison with squamous cell carcinoma by use of in vitro MR spectroscopy. Am J Neuroradiol 2000; 21: 1930-5.

[80] Mukherji SK, Schiro S, Castillo M, Kwock L, Muller KE, Blackstock W. Proton MR spectroscopy of squamous cell carcinoma of the extracranial head and neck: in vitro and in vivo studies. Am J Neuroradiol 1997; 18: 1057-72.

[81] El-Sayed S, Bezabeh T, Odlum O, et al. An ex vivo study exploring the diagnostic potential of H-1 magnetic resonance spectroscopy in squamous cell carcinoma of the head and neck region. Head Neck J Sci Spec 2002; 24: 766-72.

[82] Kunkel M, Reichert TE, Benz P, et al. Over expression of Glut-1 and increased glucose metabolism in tumors are associated with a poor prognosis in patients with oral squamous cell carcinoma. Cancer 2003; 97: 1015-24.

[83] Bhawal UK, Ozaki Y, Nishimura M, Sugiyama M, et al. Association of expression of receptor for advanced glycation end products and invasive activity of oral squamous cell carcinoma. Oncology 2005; 69: 246-55.

[84] Ujpal M, Barabas J, Kovalszky I, et al. A preliminary comparative study of the prognostic implications of type 2 diabetes mellitus for patients with primary gingival carcinoma treated with surgery and radiation therapy. J Oral Maxillofac Surg 2007; 65: 452-6.

[85] Pogue BW, Krishnaswamy V, Laughney A, et al. Spectral scatter scanning system for surgical margin detection. Head \& Neck Oncology 2009; 1(Suppl 1): O12.

[86] Conti C, Ferraris P, Giorgini E, et al. Microimaging FT-IR of Head and Neck Tumours. The case of salivary glands. Head Neck Onco 2009; 1(Suppl 1): O13.

[87] Bradley G, Odell EW, Raphael S, et al. Abnormal DNA content in oral epithelial dysplasia is associated with increased risk of progression to carcinoma. Br J Cancer 2010; 103(9): 1432-42.

[88] Fend F, Emmert-Buck MR, Chuaqui R, et al. Immuno-LCM: Laser capture micro dissection of immunostained frozen sections for mRNA analysis. Am J Pathol 1999; 154: 61-6.

[89] Ziober BL, Mauk MG, Falls EM, et al. Lab-on-a-chip for oral cancer screening and diagnosis. Head Neck 2008; 30(1): 111-21.

Received: August 27, 2014

Revised: December 15, 2014

Accepted: May 25, 2015

(c) Esam Omar; Licensee Bentham Open.

This is an open access article licensed under the terms of the Creative Commons Attribution Non-Commercial License (http://creativecommons.org/licenses/by-nc/3.0/) which permits unrestricted, non-commercial use, distribution and reproduction in any medium, provided the work is properly cited. 